\title{
Investigation of Light Non-Aqueous Phase Liquid Migration Single and Double-Porosity Soil Using Light Transmission Visualization Method (LTV)
}

\author{
Motasem Y. D. Alaziaza, ${ }^{1, a}$, Su Kong Ngien ${ }^{1}$, Mustafa M. Bob ${ }^{2}$, Samira A. Kamaruddin ${ }^{3}$ and Wan Mohd \\ Faizal Ishak ${ }^{4}$ \\ ${ }^{1}$ Faculty of Civil Engineering and Earth Resources, Universiti Malaysia Pahang, 26300 Gambang, Kuantan, \\ Malaysia \\ ${ }^{2}$ Department of Civil Engineering, College of Engineering, Taibah University, Madinah, Saudi Arabia \\ ${ }^{3}$ Razak School of Engineering and Advanced Technology, Universiti Teknologi Malaysia, 54000 Kuala Lumpur, \\ Malaysia \\ ${ }^{4}$ Centre of Earth Resources Research and Management, Universiti Malaysia Pahang, 26300, Gambang, Kuantan, \\ Malaysia
}

\begin{abstract}
Two experiments were conducted to investigate the migration of light non-aqueous phase liquid (LNAPL) in two different porous media using LTV technique. The first media was fine sand as a single-porosity and the second media was S300 kaolin as a double-porosity. The two media were packed separately in the flow chamber and then LNAPL was injected from the top of the model and the migration of LNAPL (Toluene) was observed using a digital camera connected to a laptop and controlled using special software. The images were captured according to a predetermined time interval set by the software. The results show a significant difference in the migration of LNAPL in the two porous media, where the migration in the double-porosity media was much faster than the migration in the single-porosity. This finding is due to the occurrence of inter-aggregate pores in the double-porosity soil structure. This paper shows that more attention should be given towards the pollution of the groundwater sources that are located within or near the double-porosity media especially the agricultural soil.
\end{abstract}

\section{Introduction}

Contamination from leakage of underground storage tanks and huge pipelines is the main pollution hazard to the groundwater compared to other sources. These contaminants which are known as nonaqueous phase liquid (NAPL)have a low solubility in water and occur in the subsurface as a separate phase and are considered as one of the most spread hazardous chemical [1]. Based on the density of liquids, NAPLs are classified into two types: the first type is light non-aqueous phase liquid (LNAPL) which has density less than water and the second type which is termed dense non-aqueous phase liquid (DNAPL) is denser than water. LNAPL include many hydrocarbon fuel components, for instance, toluene, benzene, xylenes (BTEX) and ethyl benzene. Tetrachloroethylene (PCE) and trichloroethylene (TCE) are examples of DNAPL materials [1]. The migration of LNAPL in

\footnotetext{
${ }^{a}$ Corresponding author : my.azaiza@gmail.com
} 
subsurface system depends on its relative density. When LNAPL enter the subsurface system, it will pass through unsaturated soil and migrate downward due to gravity and float on the surface of water table[2] resulting in deterioration of groundwater quality. On the other hand, DNAPL will pass through unsaturated zone and continue its downward migration under the effect of gravity until it reaches the saturated zone [3]. Experimental technologies such as non-invasive imaging techniques have gained more attention during the last decades which make the characterization and understanding of the multiphase system more accurate [4]. A number of image analysis techniques have been used previously to investigate and measure multiphase fluid contents in laboratory experiments [5]. Accordingly, LTV technique based on image analysis is one of the most important and promising techniques. The theory of this method depends on the passing of electromagnetic energy through the tested media where the distribution of liquid saturation is measured as variation in light intensity field. There is a linear relationship between saturation and light intensity due to closer matching between refraction index of the matrix and water relative to the matrix and air [6]. TheLTV experiments are usually conducted using a thin flow chamber connected with a fan for cooling the chamber and a built in lighting source behind the flow chamber. LTV is considered a cheap technique and requires only limited equipment [7]. This paper investigates the migration of LNAPL in two different types of porous media, the first media is single-porosity soil and the second media is double-porosity soil using LTV technique. The materials that used arenatural fine sand as a single-porosity and S300 kaolin as a double-porosity. The migration of LNAPL was monitored using digital camera and capturing of the photos was carried out according to specific time intervals.

\section{Materials and Methods}

\subsection{Experimental setup}

A 2-D flow chamber made of acrylic was used in our experiments. The dimensions of the flow chamber were $45 \mathrm{~cm} \times 30 \mathrm{~cm} \times 1 \mathrm{~cm}$. The light box contains light source consisted of three $18-\mathrm{W}$ fluorescent tubes (OSRAM, L18W/780 SMARTLUX, Sky White, Malaysia). The flow chamber was packed with the porous media and fixed inside steel frame in front of the light source. A digital cameraNikon D7100(Nikon SDN, BHD, Malaysia) was fixed on the same position during the experiments at a distance of $1 \mathrm{~m}$ from the light box. The camera captured images that has 24 mega pixels $(6000 \times 4000$ pixels), and a 14 bit dynamic range that results in 16,384 grey levels. The camera was connected to a laptop and the capturing of the images was controlled by Nikon camera control pro 2 software. The setup of the experiment is shown in Figure 1.

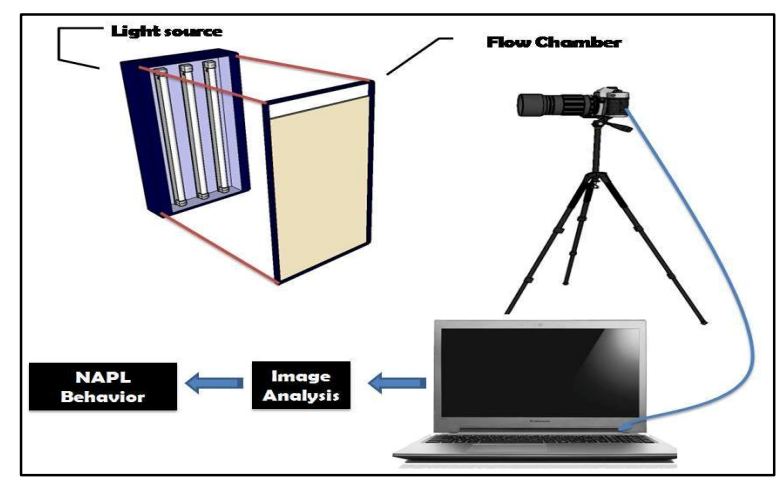

Figure 1. Experimental setup. 


\subsection{Preparion of porous media and LNAPL}

The first media was natural fine sand which retained on sieve $212 \mu \mathrm{m}$. The sand was washed with water and dried in the oven for 48 hours at $45^{\circ} \mathrm{C}$. After drying, the sand was packed by pouring layer by layer into the flow chamber through a funnel, and then tapped the outer frame of the model using a plastic hammer to achieve a dense pack. The other media was S300 kaolin which presents the doubleporosity soil structure. To create the double-porosity structure, the procedure in previous study[8] was followed. The powdered kaolin was weighted and mixed with determined water quantity with hand to get a water content of $30 \%$. This percentage was chosed because kaolin starts to disintegrate at $35 \%$ water content [9]. After mixing the kaolin with water, it was placed in a sealed plastic bag for $24 \mathrm{~h}$. Then, the mix was broken by hand and passed through a $2.36 \mathrm{~mm}$ sieve to obtain the granules structure of the kaolin. The same procedure was repeated to pack the model with kaolin, but the difference here was the compaction process was using a rectangular piece made of acrylic with the same width of the model. Each experiment used $50 \mathrm{ml}$ toluene as a LNAPL. Since the LNAPL is colorless, $0.1 \mathrm{~g}$ of Oil Red $\mathrm{O}$ was used to dye the LNAPL for better visualization. Kechavarzi et al.[10] has stated that mixing a small amount of dye is enough. This concentration is deemed to be sufficient to facilitate good visual observation of the LNAPL movement through the acrylic wall of the flow chamber. The dye was weighted and then the toluene was added and mixed with the dye using spatula. The LNAPL was injected using injection syringe needle from the top of the model. The needle was pushed to penetrate the soil to about $2 \mathrm{~cm}$ below the top of the model before LNAPL was released to allow the movement of it downward directly and avoid the movement of the LNAPL on the top of the soil.

\subsection{Image acquisition}

After the injection of the LNAPL, the digital camera starts to capture images automatically based on predetermined time intervals. Table 1 lists the time intervals for image acquisition for the two porous media.

Table1. Frequency of image acquisition.

\begin{tabular}{|c|c|c|}
\hline \multirow{2}{*}{ Period (min) } & \multicolumn{2}{|c|}{ Frequency Interval } \\
\cline { 2 - 3 } & Single-porosity (sec) & Double-porosity (sec) \\
\hline $0-6$ & - & 5 \\
\hline $6-9$ & - & 10 \\
\hline $9-12$ & - & 30 \\
\hline After12 & - & 60 \\
\hline $0-50$ & 15 & - \\
\hline $50-110$ & 30 & - \\
\hline $110-212$ & 60 & - \\
\hline $212-270$ & 180 & - \\
\hline After 270 & Randomly according to the change & - \\
\hline
\end{tabular}




\section{Results and Discussion}

\subsection{Single-porosity experiment}

According to Figure 2, the migration of the LNAPL was very slow and the change in the behavior and movement of the LNAPL is very small. It was also observed that the migration of the LNAPL in the sand was fast during the first hour, and then the migration decreased slowly. This behavior is the same in the case of horizontal direction. It can be concluded that rabid toluene migration occurred during the first $1 \mathrm{hr}$, and later the migration rate becomes slower.

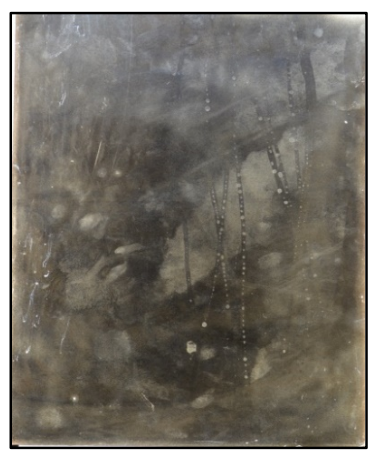

(a)

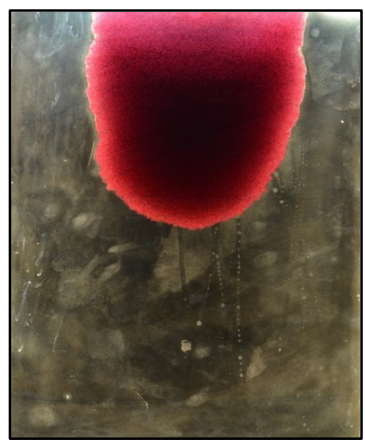

(d)

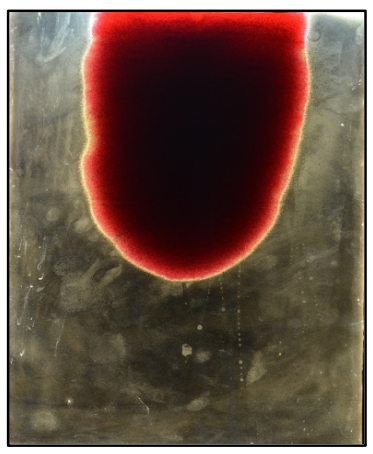

(g)

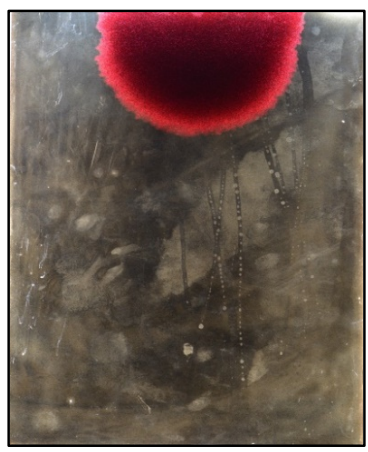

(b)

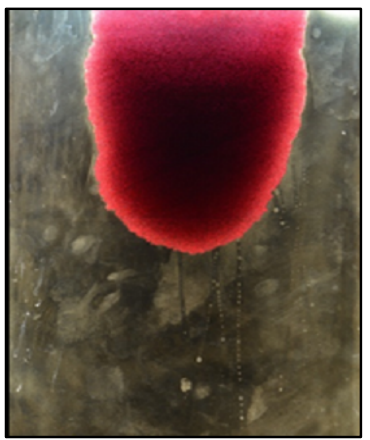

(e)

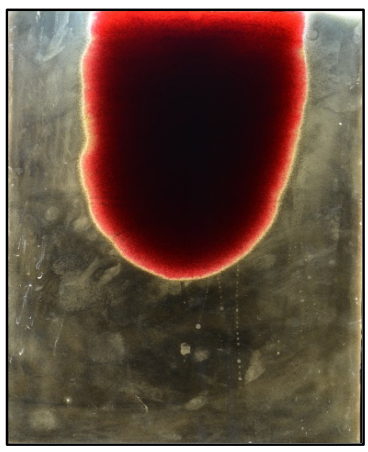

(h)

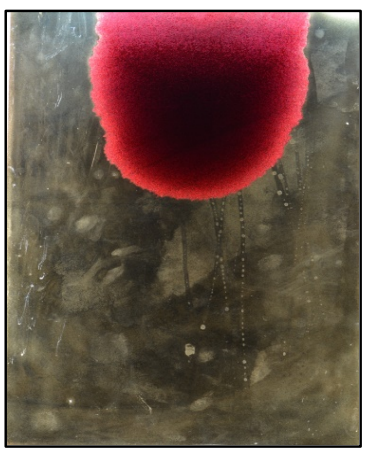

(c)

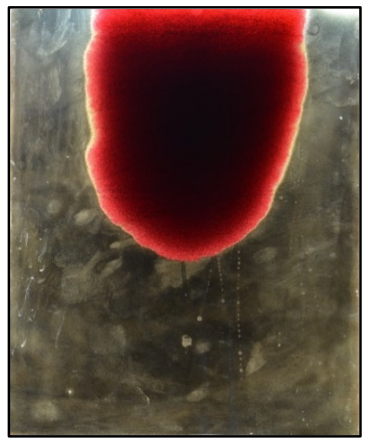

(f)

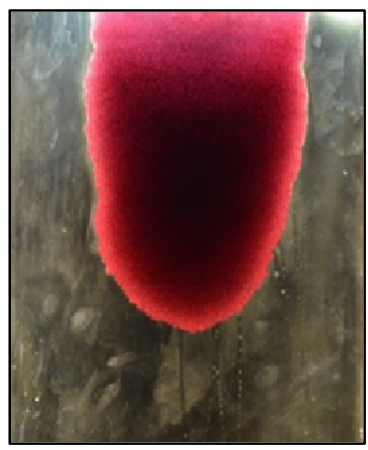

(i)

Figure 2. Toluene migration in single-porosity soil after (a) $0 \mathrm{sec}$ (b) $1 \mathrm{~min}$ (c) $5 \min$ (d) $10 \mathrm{~min}$ (e) $30 \mathrm{~min}$ (f) $1 \mathrm{hr}$ (g) $5 \mathrm{hr}(\mathrm{h}) 1$ day (i) 4 days. 


\subsection{Double-porosity experiment}

Based on the captured images shown in Figure 3, a significant difference in the velocity of migration of the LNAPL occurs in double-porosity kaolin media.LNAPL reached the bottom of the model in 27 minutes and stopped the migration in 44 minutes. This is due to the occurrence of inter-aggregatepores (secondary porosity) between the kaolin granules. This result was observed previously as mentioned by Ngien et al. [11] when they compared the migration of LNAPL between single and double-porosity soil using light reflection method. Furthermore, it was observed that the migration of LNAPL in double-porosity soil is fast in the horizontal direction.

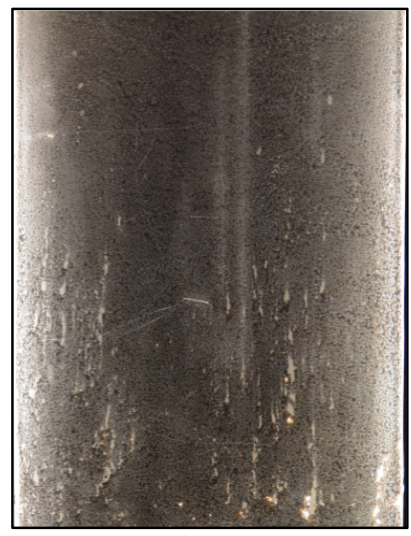

(a)

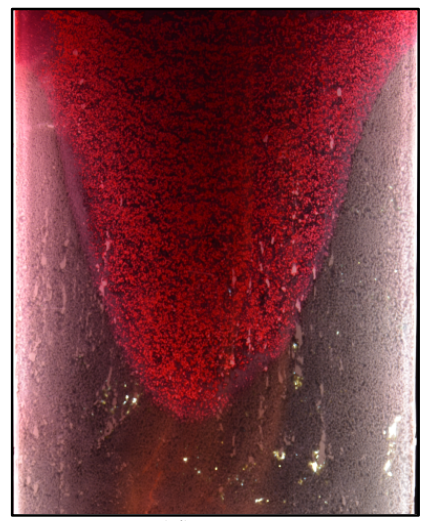

(d)

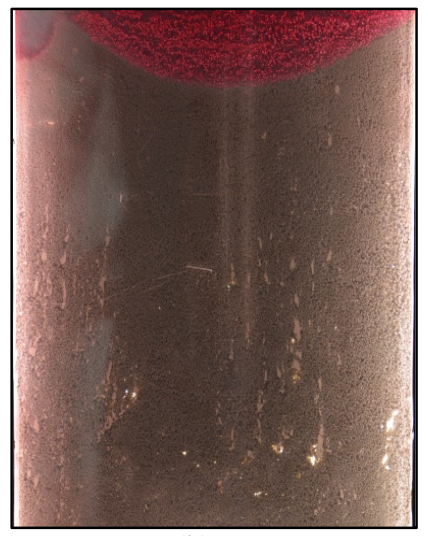

(b)

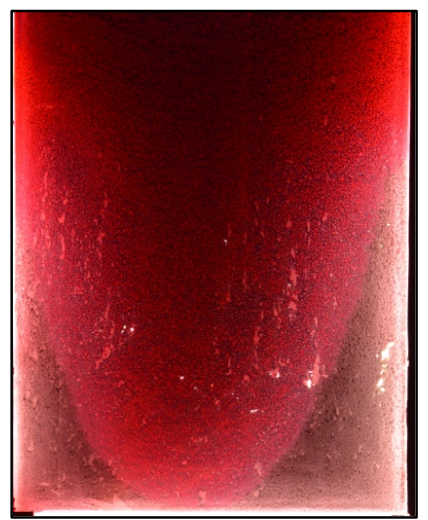

(e)

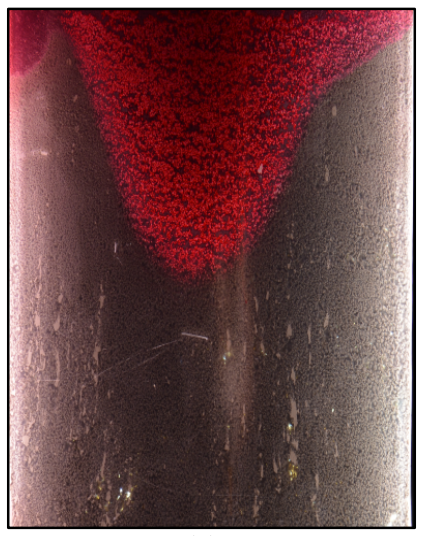

(c)

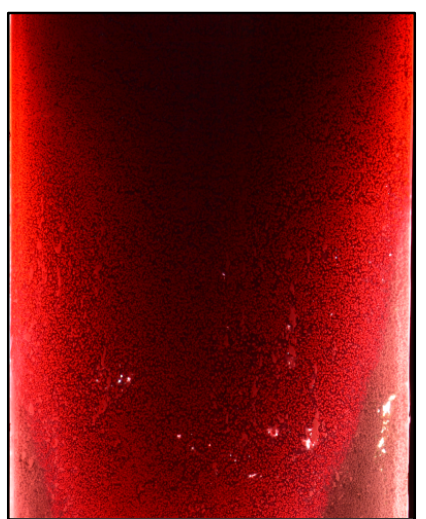

(f)

Figure 3. Toluene migration in double-porosity soil after (a) $0 \sec$ (b) $5 \sec$ (c) $30 \sec$ (d) $1 \min$ (e) $27 \min$ (f) 44 $\min$.

Based on the observations, it was noticed that at the first moments of LNAPL injection, the migration of the LNAPL was very fast during the first minutes. This is obvious in Fig. 3 (c) and (d), where LNAPL had migrated about half the model depth during the first 30 seconds and about three quarter in 1 minute. However, after 1 minute, the migration was decreasing slowly and this is clear in Fig. 3 (e), where LNAPL take about 26 minute to migrate from the three quarter the model depth to reach the bottom of the model. After LNAPL reaches the bottom of the model, its migration continue but in the horizontal direction as shown in Fig. 3 (f). This may be due to the higher compaction in the bottom of the model than of the top of the model. The more compaction in the bottom of the model resulted in smaller inter-aggregate pores which led to slower migration than the top of the model. 


\section{Conclusions}

Laboratory experiments using LTV technique were conducted to investigate the migration of the LNAPL in single-porosity and double-porosity soil structures. The results show a significant difference in the migration movement of the LNAPL through the two media. The migration of the LNAPL in double-porosity soil was much faster than the migration in single-porosity. This is most likely due to the occurrence of the inter-aggregate pores in the double-porosity soil structure. This finding depicts the risk of the pollution in the groundwater sources that are located in the region of double-porosity soil especially agricultural soil through which the contaminants will diffuse very fast compared with other types of soil. Further studies are needed in this area of research using LTV especially the migration of LNAPL under different conditions for double-porosity soil such as fully and partially saturated.

\section{References}

[1] C.J. Newell, S.D. Acree, R. Ross and S. Huling, Ground water issue: Light nonaqueous phase liquids, U.S. Environmental ProtectionAgency. Groundwater Services, Houston, (1995).

[2] B.L. Morris, A.R. Lawrence, P. Chilton, B. Adams, R.C. Calow and B.A. Klinck, Groundwater and its susceptibility to degradation: A global assessment of the problem and options for management, J. Early Warning and Assessment Report Series, RS. 03-3. United Nations Environment Programme, Nairobi, Kenya. (2003).

[3] K. Soga, J. Page and T.A. Illangasekare, Review of NAPL source zone remediation efficiency and the mass flux approach, J. Journal of Hazardous Materials, 110, 13-27, (2004).

[4] B. Agaoglu, N.K. Copty, T. Scheytt and R. Hinkelmann, Interphase mass transfer between fluids in subsurface formations: A review, J. Advances in Water Resources, 79, 162-194, (2015).

[5] M. Oostrom, J. Dane and T.W.A. Wietsma, Review of multidimensional, multifluid, intermediate-scale experiments: Flow behavior, saturation imaging, and tracer detection and quantification, J. Vadose Zone Journal, 6, 610-637, (2007).

[6] R.J. Glass, T.S. Steenhuis and J.Y. Parlange, Mechanism for finger persistence in homogeneous, unsaturated, porous media: Theory and verification, J. Soil Science, 148, 60-70, (1989).

[7] H. Wang, X. Chen and J.W. Jawitz, Locally-calibrated light transmission visualization methods to quantify nonaqueous phase liquid mass in porous media, J. of Contaminant Hydrology, 102 , 29$38,(2008)$.

[8] A. Bagherieh, N. Khalili, G. Habibagahi and A. Ghahramani, Drying response and effective stress in a double porosity aggregated soil, J. Engineering Geology, 105, 44-50, (2009).

[9] R. Sa'ari, N. Rahman, Z. Yusof, S. Ngien, S. Kamaruddin and M. Mustaffar, Application of digital image processing technique in monitoring LNAPL migration in double porosity soil column, J. Jurnal Teknologi, 72, 23-29, (2015).

[10]C. Kechavarzi, K. Soga and P. Wiart, Multispectral image analysis method to determine dynamic fluid saturation distribution in two-dimensional three-fluid phase flow laboratory experiments, J. Journal of Contaminant Hydrology, 46, 265-293, (2000).

[11] S.K. Ngien, N.A. Rahman, M.M. Bob, K. Ahmad, R. Sa'ari and R. W. Lewis, Observation of light non-aqueous phase liquid migration in aggregated soil using image analysis, J. Transport in Porous Media, 92, 83-100, (2012). 